\title{
Compare Auto- finance Product Pricing Model
}

\author{
Xuetao Li \\ Department of Economics and Management \\ Hubei University of Automotive Technology \\ Shiyan, China \\ E-mail:857890008@qq.com
}

\begin{abstract}
Automotive financial services product development, innovation and design technology is the basis for auto finance industry and the basic means of survival, based on the trend of China's legal and policy environment, the automotive market characteristics and behavioral characteristics of consumer psychology, consumer products and more selective more from the consumer point of view, to solve consumer psychology and behavior. In this paper, options knowledge, the design of automotive financial products option pricing model, and general product on the market to compare pricing models derived option pricing model is more suitable for consumers to choose more type automobile pricing of financial products conclusions.
\end{abstract}

Keywords-Auto-finance; Automotive Financial products; Option pricing

\section{INTRODUCTION}

Automotive financial products like insurance and finance products, refers to the use of that car financing transactions and financial structures performed (number, duration, cost, etc.), financial strategy design and corresponding legal contractual arrangements, is in reality automotive financial services facing questions. Automotive Financial Services products are based on the market supply and demand situation, the subject matter of the trade value of the car-based, service as a means to financial operations as the main consumer demand for different groups of objects for the design, the development of series of tradable financial instruments, financial services and various financial strategies design. Pricing as a product design the most important aspect, this article focuses on product pricing models, comparative analysis of automotive financial products generally pricing and option pricing approach.

\section{GENERAL INSTALLMENTS PRODUCT PRICING}

Mortgage loans are usually repaid in various ways. At present, the domestic commercial mortgage repayment methods are mainly two: one is equal principal and interest repayment, the other is equal principal repayment.

\section{A. Equal Installments of Principal and Interest Repayment}

Equal installments of principal and interest repayment is the borrower in the life of the loan principal and interest of the loan and the use of equal monthly payments of a repayment method. Over one year (does not contain a year) of individual housing loans repayment methods can be used in this way. The monthly repayment amount of the debt due the same way, more suitable for the entire term of the loan has a stable source of household income borrowers, such as organs and institutions, including school staff and so on. Equal monthly installments of principal and interest repayment is calculated as

$P M T_{m}=P \times R_{m}=\frac{P \times R_{m}}{\left(1+R_{m}\right)^{N_{m}}-1}=P \times \frac{R_{m} \times\left(1+R_{m}\right)^{N_{m}}}{\left(1+R_{m}\right)^{N_{m}}-1} P M T_{m}$ Equal monthly principal and interest for the repayment of the loan amount; $\mathrm{P}$ is the loan principal; rate for the month; loans total number of months.

Typically, the loan principal is 1 yuan when the corresponding calculated amount equal monthly repayment of loan principal and interest, said

Secured by constant use, said:

$$
M=\frac{R_{m} \times\left(1+R_{m}\right)^{N_{m}}}{\left(1+R_{m}\right)^{N_{m}}-1}
$$

Repayment in equal installments of principal and interest, for the repayment of principal is conducted monthly. In the early repayment, repayment of the amount of interest attributable to a great part; With the passage of time, the amount of interest repaid gradually reduced, increasing the principal; and in the repayment period, repayment of the principal amount of the share great parts. In equal installments of principal and interest repayment, if interest rates unchanged, you can repay the loan principal and interest equal monthly annuity as a total loan amount is the present value of the annuity period, and thus the repayment of the loan balance is the month after the end of the month annuity present value. Months after the repayment of the loan balance is calculated as:

$$
P_{t}=\frac{P M T_{m} \times\left(1+R_{m}\right)^{N_{m}}-1}{R_{m} \times\left(1+R_{m}\right)^{N_{m}}}
$$

\section{B. Equal principal repayment}

Equal principal repayment of the loan amount the borrower apportioned equally to the entire life of the loan, monthly (period) equal repayment of the principal, and pay on a loan interest since a repayment. In this manner, the amount of each repayment period decreased by, more suitable for a certain savings, but may gradually reduce the expected income borrowers, such as some middle-aged workers, you can choose this method of repayment. Monthly principal repayment is calculated as: 


$$
\begin{aligned}
& P_{m}=\frac{P}{N_{m}} \\
& I_{t}=\left[P-P_{m}(t-1)\right] \times R_{m} \\
& P I_{t}=P_{m}+I_{t}
\end{aligned}
$$$$
P_{m} \text { for the repayment of the principal amount equal }
$$
monthly;P for the loan principal; $R_{m}$ For the monthly interest rate; $N_{m}$ The total number of months of the loan; $I_{t}$ for to repay the amount of interest the $\mathrm{t}$ month; $P I_{t}$ for the $\mathrm{t}$ month to repay the loan principal and interest amount.

\section{AN EMBEDDED OPTION PRICING}

\section{A. Models and Algorithms}

Mathematicians tend to use other methods can not be resolved or very difficult to consider the application of simulation technology solutions when solving problems, but investors are always willing to use a method of calculation of all portfolios, financial intermediaries were happy to have a way to analyze entire assets - liabilities, and simulation methods to meet this demand. The market is changing, many factors affect asset prices, through the establishment of rigorous nonlinear partial differential equation model to get the price of assets and their derivatives approximate solution is very difficult, using simulation methods to solve problems has become a good and practical selection. This paper attempts to use computer simulation methods to pricing fixed-rate mortgage contract default and prepayment options, the model assumes a fixed interest rate mortgage contract

1) Amount of repayment.

This document defines a standard economic environment, assuming the value of the mortgage interest rate irrelevant material.

a). Fluctuations in the value of the mortgage to follow Wiener process:

$$
\frac{d H}{H}=(a-s) d t+s_{H} d z_{H}
$$

a -Expected return on the mortgage property; ${ }^{s}-$ depreciation rate mortgages compounds; $S_{H}-$ the standard deviation of the mortgage property; $z_{H}$ —standard Wiener process

b). According to Cox, Ingersoll and Ross (1985) theory of the term structure of interest rates is the square root of the mean reversion process:

$$
d r=g(q-r) d t+s_{r} \sqrt{r} d z_{r}
$$

$g$ _ Adjust the speed; $q$ - steady rate; $S_{r}$ - rate standard deviation; $z_{r}$-standard Wiener too

\section{2) Decision Criteria}

According to (1.1) (1.2) Analog each payment date and the value of the current mortgage interest rates for the second simulation times. In each repayment date lenders have three options: default, normal pay, early repayment. Loan repayment date in each cost minimization objective function to make decisions. Using Leung and Sirmans (1990) criteria to measure the cost of various options:

a). normal costs incurred: $M P+M B(i, k)$

b). the cost of default: (1 a) $H(i, k)$

3) the cost of early repayment: $(1+b) ? R B(i) \quad M P$

Of which:

$M P$ (Mortgage Payment) :Amount of each payment; $M B(i, k)$

(Mortgage Balance) :Path k i in mortgage payment date material account balance;

$\mathrm{H}(\mathrm{i}, \mathrm{k})$ :Path $\mathrm{k} \mathrm{i}$ in the value of the mortgage payment date;

RB (i) ( Remaining Balance) :repayment mortgage account balance

$b$ : Refinancing costs

a: default penalty factor

$\mathrm{i}=1,2, \ldots, \mathrm{T} ; \mathrm{T}$ for the number of mortgage payments

$\mathrm{k}=1,2, \ldots, \mathrm{K} ; \mathrm{K}$ for frequency of the analog

When $\mathrm{i}=\mathrm{T}$, that is, until the contract period, the lender in the normal payments and defaults to choose between

The value of $\mathrm{M}$ is a mortgage:

$\mathrm{M} \quad(\mathrm{i}, \mathrm{k})=\min \{\mathrm{MP}+\mathrm{MB}(\mathrm{i}, \mathrm{k} \quad),(1+\mathrm{a} \quad) \times \mathrm{H} \quad(\mathrm{i}$, $\mathrm{k}),(1+\beta) \times \mathrm{RB}(\mathrm{i})+\mathrm{M}$

Where $\mathrm{i}=1,2, \ldots, \mathrm{T}-1 ; \mathrm{k}=1,2, \ldots, \mathrm{K}$

$\mathrm{M}(\mathrm{T}, \mathrm{k})=\min \{\mathrm{MP},(1+\mathrm{a}) \times \mathrm{H}(\mathrm{i}, \mathrm{k})\}$

Where $\mathrm{k}=1,2, \ldots, \mathrm{K}$

Define the state variables (State Index) SI (i, k) values and their meanings are:

SI $(i, k)=0$, 当 $M(i, k)=(1+a) \times H(i, k)$,means that borrowers choose to default;

SI $(\mathrm{i}, \mathrm{k})=1$, 当 $\mathrm{M}(\mathrm{i}, \mathrm{k})=\mathrm{MP}+\mathrm{MB}(\mathrm{i}, \mathrm{k})$,Indicates normal performance of mortgage lenders contract

$\mathrm{M}(\mathrm{i}, \mathrm{k})=(1+\beta) \times \mathrm{RB}$ (i $)+\mathrm{MP}$, means that borrowers choose to pay in advance the end of the contract.

3) To solve the mortgage account balance $M B$ of dynamic programming algorithm

Based Epperson et al (1985) point of view, default options and prepayment options are complex European option, because in each payment date, the lender will default options or execute or perform early repayment option, or pay the agreed purchase price of the next issue option combinations. Since compound option value before a subsequent period by the impact of the option value, option pricing is a composite reverse recursive dynamic planning process. While the ordinary simulation technology are essentially a recursive process forward (Michael et al, 2000), the reverse is not suitable for direct solving recursive process. But Tilley (1993) proposed the "splitting method" to resolve this inherent contradiction, that before the 
application of the algorithm to simulate all of the random process. In this paper, Tilley (1993) idea of the path from the mortgage property value method to solve the mortgage account balance things MB. Mortgage property value path dynamic programming algorithm to calculate the steps of:

a). Based on the above model to simulate each Payment Date, the value of the mortgage and the current interest rate path, simulation times of $K(K=Q \times P)$ times;

$b)$. I in period to the value of the mortgage $H(i, k)$ are sorted, the sorted $H(i, k)$ is divided into $Q$ beam path of each beam with $P$;

c). The mortgage payment date account balances $R B$ (i):

$$
R B(i)=M P \times \frac{\left[1-\left(1+\frac{R}{m}\right)^{(i-t)}\right.}{\frac{R}{m}}
$$

Where: $\mathrm{i}=1,2, \ldots, \mathrm{T}-1 ; \mathrm{R}$ is a fixed rate mortgage contracts; $\mathrm{m}$ for the annual payment frequency;

To determine $M(i, k)$. $M(i, k)=\min \{M P+M B(i, k),(1+a) \times H(i, k),(1+\beta) \times R B(i)+M P\}$ Where $\mathrm{i}=1,2, \ldots, \mathrm{T}-1 ; \mathrm{k}=1,2, \ldots, \mathrm{K}$

d). To determine $S I(i, k)$ :

$$
S I(i, k)=0 \text {,when } M(i, k)=(1+a) \times H(i, k) \text {,Mean }
$$
$\mathrm{s}$ that borrowers choose to default;

$$
S I(i, k)=1
$$

$M(i, k)=M P+M B(i, k)$,Indicates normal performance of mortgage lenders contract;

$$
M(i, k)=(1+\beta) \times R B(i)+M P \quad, \quad \text { Means that }
$$
borrowers choose to pay in advance the end of the contract.

$$
i=1,2 \cdots T-1, k=1,2 \cdots K \text {; }
$$

e). Randomly selected from a bunch of midterm closest size values as a bundle of interest:

$$
r(i, k), \quad i=1,2 \cdots T-1, k=1,2 \cdots K \text {; }
$$

f). Calculation of the q beam $M B(i, k)$ :

$$
M B(i, k)=\frac{1}{P[1+r(i, k)]} \times \sum_{k=(q-1)^{p+1}}^{q^{p}} M(i+1, k)
$$

where $i=1,2 \cdots T-1 ; k=1,2 \cdots K, q=1,2 \cdots Q$;

c). $\quad i=i-1$ returns 2$)$;

Initial

$M(T, k)=\min \{M P,(1+a) \times H(i, k)\}$
Wherein $k=1,2 \cdots K$

4) Calculating the value of options

Using the same method, you can not be obtained in breach of the contract can not prepay the mortgage account balance things NDP, can not breach the contract may prepay the mortgage account balance things ND, may breach the contract can not prepay the mortgage account balance things NP, the option value are as follows:

A)The $i$ phase of default and prepayment Mixed Options:

$$
D P O(i)=\frac{1}{K} \sum_{k=1}^{K} N D P(i, k)-\sum_{k=1}^{K} M B(i, k)
$$

(2) The i phase of default options:

$$
D O(i)=\frac{1}{K} \sum_{k=1}^{K} N P(i, k)-\sum_{k=1}^{K} M B(i, k)
$$

(3) Section of i repayment options:

$$
\begin{aligned}
P O(i) & =\frac{1}{K} \sum_{k=1}^{K} N D(i, k)-\sum_{k=1}^{K} M B(i, k) \\
\text { where } i & =0,1,2 \cdots T-1
\end{aligned}
$$

\section{COMPARISON OF TwO PRICING METHODS}

Equal installments of principal and interest repayment and equal principal repayment methods generally used in the traditional automotive pricing of financial products; legal policy based on our environmental trends, the automotive market characteristics and behavioral characteristics of consumer psychology, consumer products better and more selective from consumer point of view, to solve consumer psychology and behavior, in terms of pricing of such products than the traditional option pricing models pricing models have an advantage, so that the design of such products as possible.

\section{ACKNOWLEDGEMENTS}

The paper has been supported by project (NO. 2012y050) of the Department of Education, Hubei Province China. Hereby thanks!

\section{REFERENCES}

[1] Piore M. and Sable C. The second industrial divide [M].New York:Basic Brooks, 1984 [2]Porter M E. The Competitive Advantage of Nations. The Free Press, 1990.

[3] Xuetao Lee, Shuxiu Yu. Empirical Study on Market Efficiency in Hubei-China Automotive industry Based on SCP Paradigm[C] Second International Seminar on Business and Information Management, 2010.

[4] Alfred Weber. Theory of the Location of Industries [M]. University of Chicago Press, 1962. 